\title{
Physical Education in Moroccan primary schools: What Contributions to the Development of Children's Personalities
}

\author{
Soulaiman HARFOUF \\ Interdisciplinary Research Laboratory on Pedagogical Engineering \\ Higher School of Education-Abdelmalek Essaâdi University (UAE), Tetouan, Morocco
}

\begin{abstract}
In Morocco, physical education (PE) in primary school is justified by its contribution to the integral formation of children. It has a positive impact on the development of the personality of those who invest in it. This is the reason why PE is included as a separate subject in the curricula of the different levels of the primary cycle. However, several factors minimise the effect of practising PE in schools and make it difficult for PE to make a real contribution to the development of children's personalities.

This article therefore sets out to show that in the absence of rational programming, qualified physical educators and suitable and sufficient material conditions, PE cannot claim to make a real contribution to the development of children's personality.
\end{abstract}

Keywords: Physical Education, Personnality, Development, Primary School, Sports Activities.

\section{INTRODUCTION}

Following the example of other teaching activities in the primary cycle in Morocco, Physical Education (PE) pursues objectives that are consistent with the more general objectives of education. To educate means to guide, to raise, and therefore to develop the physical and motor, psycho sociological and intellectual resources of children; if PE has been entrusted with the mission of educating children, it is undoubtedly because it is supposed to promote the development of their personality.

What do we mean by personality and development in the first place? According to Allport: "Personality is the dynamic organisation of the cognitive, affective, conative, physiological and morphological aspects of an individual" [1].

To say that the personality is a dynamic organisation is to admit that it can undergo or be transformed and evolve. These transformations can be negative as well as positive. If they are positive and lead to an evolution and growth of the personality, we will say that the personality has developed. Indeed, development by definition means growth, evolution, extension and increase, etc.

The study of personality development has been the subject of several controversies. These controversies are justified by the diversity of factors likely to influence the structuring and development of personality. These factors may be hereditary, the result of socio-cultural conditions, the result of multiple learning experiences that the individual has accumulated or the consequence of previous experiences.

The question that now arises is to what extent PE can legitimately be included in the set of factors that explicitly engender an individual's personality development [2].

Despite the affirmative answer often given in Moroccan official texts on this subject [3], our thesis has reservations about the effect of the practice of PE on the structuring and development of children's personalities and sets out to show that in the absence of rational programming of objectives and contents, of qualified and experienced educators and of suitable and sufficient material conditions, PE cannot claim to make a real contribution to the blossoming of the personalities of school children.

To show this, we organize our reasoning around three parts. In the first part, we will show the place of personality development in the objectives of PE, particularly in the Moroccan primary cycle. Then, the second part will highlight, based on scientific research, the influence of physical activities and sports games on the personality of the children who take part in them. Finally, in the third part, we will report on the major difficulties that prevent PE from making a real 
contribution to the development of the personality of schoolchildren. We will make some suggestions for overcoming them.

\section{CHILDREN'S \\ PERSONALITY DEVELOPMENT IS AT THE HEART OF THE EP'S OBJECTIVES}

A reading of the objectives assigned to $\mathrm{PE}$ in Moroccan official texts [4] clearly shows that the integration of PE in primary school programmes is justified by the conviction that it is necessary to develop children's personality. Indeed, for example, in the first article of the first chapter of the national charter of education and training (CNEF) promulgated on 19 May 2000 , we find among the general objectives of the preschool and primary cycles:

- To promote the full physical, cognitive and emotional development of the child;

- To promote the development of sensory-motor, spatial and temporal, semiological, imaginative and expressive skills;

- To consolidate the learning of basic technical, professional, sporting and artistic skills, directly linked to the socio-economic environment of the school;

- To facilitate the acquisition of fundamental knowledge and skills that develop the child's autonomy and socialization;

- The appropriation of the rules of life in society and the values of reciprocity, cooperation and solidarity.

If the CNEF describes the nature of the developments sought in children, thus enabling PE to define its area of intervention, the primary school physical education curriculum [5] explicitly answers the question of why PE should be programmed among the subjects taught in this cycle. We read:

Regular and supervised practice of PE and sports games:

- Contributes to the effective and renewed stimulation of the child's motor skills

- Helps the child to get to know himself, to adapt to his environment and to position himself in his surroundings;

- Helps the child find effective solutions to motor problems;

- Promotes the child's socialization and physical and motor independence;

- Enables the child to acquire increasingly sophisticated reference points enabling him/her to explore and better perceive time and space;

- Helps the child to control his or her actions and to adapt them to his or her objectives and to the requirements of the situation.
If the content of this text describes quite clearly the nature of the developments sought by PE at primary level, the same curriculum specific to PE at primary level expresses itself even more explicitly. First, it states that the objectives of PE are not different from the general objectives of education, which aim at the formation and development of the learner's personality in an integral and harmonious way. He then recalls that the main objective of the first cycle of primary school is to consolidate, deepen and extend the physical, motor and sports skills acquired in pre-school. He then classifies the objectives of PE into three main categories. Thus we can see:

a- Objectives focused on the development of the psychomotor dimension of the personality such as the development of motor skills, basic perceptual and motor abilities, balance, motor coordination, strength, endurance and resistance to fatigue...

b- Objectives concerning the development of the cognitive dimension of the personality, such as developing perceptive and motor skills, analysis and observation, perception of time and space and objects, reactivity...

c- Objectives focused on the development of the social and affective dimension of the personality, in this case: developing self-control, the spirit of responsibility and cooperation, sportsmanship, etc.

These are the objectives that highlight the particular educational usefulness of PE and attest to the legitimacy of its integration into pre-school and school programmes.

Moreover, in order to generate an increase in the resources of schoolchildren, $\mathrm{PE}$ as a fully-fledged teaching field takes physical activities and sports games as a privileged support [6]. Consequently, if we suppose that a development of the personality takes place, it is undoubtedly through the practice of all the programmed physical and sports activities. However, to our knowledge, there is no scientific study to date that confirms the hypothesis that, in PE, the practice of sports activities and sports games contributes to the development of children's personality. This hypothesis is therefore based more on "supposition" than on "evidence". However, reference can be made in this respect to the work done in the field of sport psychology and exercise physiology. In these fields of investigation, some research has been carried out to study the impact of the practice of Physical and Sports Activities on the dimensions of the personality of those who invest in them. What conclusions did they reach?

\section{SPORTS ACTIVITIES PERSONALITY DEVELOPMENT}


For a long time, sport has been considered an excellent field for the exercise of the individual's personality. It is generally accepted that the notions of strength, endurance, flexibility, but also initiative, courage, selfcontrol and constancy are associated with the notion of sportsman [7].

Thill, for example, argues that compared to nonsportsmen and women, sportsmen and women are more impulsive, highly energetic, more oriented towards others and more sensitive to social approval. [8].

Newman, for his part, states that the sportsman is more assertive and practical in his approach to problems [9].

These results therefore seem to be in favour of a balanced and developed social health.

However, the conclusions of Hosek seem to run counter to this. Indeed, the author found that young athletes are rather less sociable and more neurotic than non-athletic youths [10]. The results of Slusher go in the same direction as the author states that the athlete is characterised by a great pathological anxiety [11].

Some researchers have studied the personalities of sportspeople in relation to their specialities. For example, Voight \& Callaghan found that, following a team building programme, football players were more emotionally stable, performed better, were more confident and showed a greater capacity to withstand frustration. [12]. Fleurence, on the other hand, confirmed that the middle-distance runner has a tendency to be introverted at the front [13].

In perceptual-motor activities with a time constraint of half a second (handball, tennis...). Keller noted that the players are characterised by a personality trait intermediate between impulsiveness and reflection [14].

For his part, Bayer states that handball players have three psychological qualities, namely combativeness, motivation and control of emotions [15]. Swimmers, on the other hand, are distinguished according to Titku and Ogilive by emotional stability, openness, independence, the ability to overcome strong emotional tensions and a low level of anxiety [16].

Certainly, the psychological characteristics of the participants in the various sports can be explained, in part, by the structure of their previously formed personalities (before the investment in sport), but also and above all by the effect of the practice of sport, as is apparent from a certain amount of research. For example, we can cite Ismail and Trachtman [17] who carried out research using Cattel's PF to identify the psychological effects of running. The subjects exercised three times a week for 20 to 30 minutes per session. After four months of training, the subjects showed an improvement in self-esteem and imagination. El Ouardighi [18] after a longitudinal research carried out on 12-year-old footballers showed that after one year of practice at a rate of three times a week, there were significant transformations in the personality traits concerning psychological endurance and social desirability. Such changes did not occur in the control group and are therefore attributed to the football practice.

Many other studies report the benefits of active outdoor sports play in terms of fitness, motor skills, socialization, concentration, stress management and creativity. Playing outside in the open air allows children to engage in high intensity physical activity and expend energy. We summarize these benefits as follows [19]:

a- Good growth: specialists in exercise physiology agree that physical activity promotes healthy growth and development. Rowland T.W., for example, has shown that by moving, children master more and more motor skills and exercise their muscles. This develops strength, power and endurance. Regular stretching exercises also increase flexibility. Finally, physical activity is a good opportunity for children to improve their coordination as well as their posture, agility and balance.

b- Physical fitness: An active person's cardiorespiratory and cardiovascular capacity increases, which helps control weight and blood sugar or cholesterol levels. Physical activity therefore reduces the risk of heart disease, diabetes, obesity and certain types of cancer in adulthood.

c- Weight: Physical activity is a good way to increase calorie expenditure. Being active can reduce the risk of becoming overweight or obese. This is especially important because people who are obese in childhood are more likely to remain obese as adults.

d- Bones: Activities that require the child to bear weight, such as climbing, or jumping, increase bone density and strength. This type of activity would also improve the internal organisation of the bones, making them stronger.

e- Emotional health: Active children have higher selfesteem, more confidence and a better body image. Physical activity also helps to reduce stress and symptoms of depression and anxiety.

f- Socialization: Physical activity is an opportunity for children to develop their social skills and relationships with others. Moving around would therefore help to break isolation and promote social integration.

g- Academic success: Physical activity can improve school performance for several reasons. Firstly, sports require memorising rules and sequences of movements or making quick decisions. Secondly, movement is thought to activate certain areas of the brain and increase the blood supply to them. In addition, the confidence and relaxation provided by physical activity is thought to stimulate a child's intellectual abilities. Finally, young people who are active are said to behave better and 
develop a greater sense of belonging to their school. All these factors would help the child to function better at school.

The presentation of this research is sufficiently revealing of the structuring action that the practice of sports activities has on the personality of those who engage in them.

\section{LIMITS OF PERSONALITY DEVELOPMENT IN PE AND PROPSALS}

If sports activity generates generally positive changes in personality, is it the same when it comes to the practice of sports activities in primary schools? In reality, there are several reasons why these processes are random. If PE only becomes an official compulsory subject in the primary cycle, it is practically absent during the three (or two) years of pre-school. During the school year, preschool children only benefit from a few hours of discontinuous and random physical activities, insufficient to stimulate the development of their resources. When they reach the next cycle, these children arrive with a flagrant psychomotor delay, making it difficult to pursue the specific objectives of PE in the primary cycle.

It is therefore essential that, from pre-school onwards, educational content favouring the integral development of children is taught. It is then that the inclusion of physical education as a pedagogical discipline becomes indispensable among the fundamental knowledge to be taught from early childhood.

Moreover, if we admit with Pineau [20] that the first step towards the operationalisation of the objectives of P.E. is dependent on the choice of teaching contents, then we will understand that the effective implementation remains suspect if not illusory if the teaching contents are not clearly defined or do not fit into their logical extension. However, in the various texts governing PE at primary level, the allusion to teaching content in the form of a guide from 2011 [21] intended to guide the action of teachers by offering them milestones for their work remains insufficient. As a result, each teacher chooses his or her content according to his or her own representations and competences, which risks leading to disparity in the teaching provided and making systematic and tangible development of the various dimensions of the pupils' personality uncertain.

Thus, in order to establish coherence between the objectives of PE and the contents that operationalise them, it will be necessary to define the latter in detail and translate them into national guidelines that are both general and flexible.

Furthermore, the amount of time reserved for physical education in primary school (one hour per week) makes personality development insignificant. In France, Gazorla [22] estimated that the duration of physical activity in PE represents only $1.3 \%$ of the total physical activity of the child in a state of alertness outside of school. Another difficulty is the duration of the pupil's effective motor commitment during a PE session. According to a study carried out by Marcos and a number of student teachers in the context of teaching courses, this duration does not generally exceed 10 to 15 minutes.

Moreover, the programming of $\mathrm{PE}$ is designed on the basis of a time division by weeks, one reserved for diagnostic evaluation, weeks for the development of resources, one for integration and the last for evaluation. In practice, one hour of PE per week for each school level is actually provided in very few primary schools. This makes the duration of practice very insufficient to hope for a tangible development of pupils' skills.

Now, when we know that the results of motor learning in an APS only begin to be objectively identifiable after a cycle of 12 successive sessions of 2 hours each, as mentioned by Senners [23], it is difficult to understand how the PE teacher can claim to be able to develop the resources of his pupils after just a few learning sessions. It becomes imperative to increase the weekly volume of time allocated to the PE session. This solution will result in a reduction in the number of opportunities offered to pupils to practice several PSAs for a reasonable period of time and consequently to take advantage of their respective educational stakes.

Finally, the rudimentary material conditions in which PE is taught in primary schools cannot be ignored, as they do not allow for the completion of learning and therefore do not favour the development of the pupils' personality. Primary schools in Morocco have an undeniable lack of sports infrastructure (sports fields, equipped areas, running tracks, changing rooms, etc.) and of equipment and teaching and sports materials. This insufficiency limits the didactic and pedagogical choices of the teachers and is less motivating for the pupils who are forced to practice PE in deplorable conditions. This difficulty, added to the others, means that we are always dealing with pupils in the familiarization-initiation phase, if not with motor illiterates.

\section{CNCLUSION}

The main objective of the Moroccan education system's primary cycle is to enable the integral and permanent training of pupils in all dimensions of their personality, according to their abilities and possibilities. Physical and sports education plays an active role in the pursuit of this objective by focusing on the psychomotor dimension without losing sight of the social, effective and cognitive aspects. In order to achieve this, PE makes preferential use of Sports Activities because of their potential educational and developmental value. 
However, and despite the affirmative answer often disseminated in official texts about the considerable contribution of PE in the development of children's personality, the context of implementation of the teaching of this discipline minimizes the expected output of this subject and makes a real contribution to the development of the personality of those who invest themselves in it uncertain.

In order for this to be possible, it is essential that, from the pre-school level, PE becomes a compulsory subject teaching educational content designed and organized in such a way as to promote the integral development of children. It is then that the inclusion of physical education as a pedagogical discipline becomes indispensable among the fundamental knowledge to be taught from early childhood.

On the other hand, PES in primary schools must benefit from a significant amount of time, as one hour of PES per week is a derisory amount to pursue an objective that requires a sustained and continuous investment. At the same time, and to accompany the achievement of this goal, teachers must update and revise their knowledge and previous experience in physical education to support the effectiveness of their educational contributions. This is a prerequisite for them to appreciate the importance of the body, play and motor skills and to promote them as part of their children's education in PE. The improvement of the guide made available to primary school teachers for teaching Physical and Sports Activities is also becoming an urgent necessity. This guide must also take into consideration the particular requirements of the group of children, the variety of contexts, spaces, times, resources, the institution and the specific characteristics of the contents (PSA or others).

Finally, the material conditions must be improved so that the teaching of PE at primary level can take place normally, thus increasing the chances of successful learning while promoting the processes of personality development of pupils.

\section{NOTES AND REFERENCES}

[1] Allport G. W., (2009), cit in : Demont E., La psychologie chapter n 13 La Personnalité, pages 195 à 217.

[2] Ouardighi, K. s'était déjà interrogé en 1999 sur la véritable participation de l'EPS dans le processus de l'épanouissement physique, intellectuel et moral des lycéens marocains.

[3] The various official texts that have governed the teaching of PE in Moroccan primary schools since it became compulsory in 1964.

[4] We refer here in particular to the National Charter of Education and Training and to Law 30-09 on Physical Education and Sport 2009. Unpublished document.

[5] Curriculum for the teaching of PE in the primary cycle, Directorate of Curricula, Moroccan Ministry of National Education, 2011.
[6] Since 1977, PE has favoured PSA as an almost exclusive means of education in all educational cycles where PE is well established.

[7] Gasparini, W., (2008), Integration through sport: the political genesis of a collective belief. In: Contemporary Societies, $\left(\mathrm{n}^{\circ}\right.$ 69), pages 7 to 23 .

[8] Thill E., (1975), Sport and Personality, edited by J.-P. Delarge. Paris

[9] Newman, O., (1972). Defensible Space; Crime Prevention through Urban Design. New York: Macmillan. Newman, O. (1980). Community of Interest. Garden City, NY: Anchor Press/Doubleday.

[10] Hosek, A., and al. (1982). Relations between sports and sorne factors intluencing the socialization process. International review of sport sociology17 (4), 39-46., Cit. in: Charest P., (1999). Aspects of personality and asociality in different types of athletes aged 14-17 years. Dissertation presented for the master degree of physical activity science, Québec à trois-rivières University.

[11] Slusher, H. S., (1964) Personality and Intelligence Characteristics of Selected High School Athletes and Nonathletes, Research Quarterly. American Association for Health, Physical Education and Recreation, 35:4, 539-545, DOI: $10.1080 / 10671188.1964 .10613351$

[12] Voight, M., \& Callaghan, J. (2001). A team building intervention program: Application and evaluation with two university soccer teams. Journal of Sport Behaviour, 24 (4), 420-431.

[13] Fleurance, P., (1998). Mental training and high performance sport. In: Les cahiers de L'I.N.S.E.P., n ${ }^{\circ} 22$. Institute of Sport and Physical Education, France.

[14] Keller M., (1982). Quoted by: Courneya, K. S. (1998), in: Personality correlates of Exercise Behaviour. Motives, Barriers and Preferences: An application of the Five-Factor-Model. Pers. Individ. Dif ( $\left.\mathrm{N}^{\circ} 5\right)$, 625-633.

[15] Bayer, C., (1983). Handball: the player's training. Editions Vigot, Paris, France.

[16] Titku, T. and Ogilive, B., (1981). Problem athletes, trainertrainee relationship. Editions Vigot. ISBN-10 2711408337: ISBN-13:9782711408337.

[17] Ismail, A. H., \& Trachtman, L. E., (1973). Jogging and imagination. Psych. Today, 6:79.

[18] Ouardighi K., (1988). Effects of football practice on the psychological and social behaviour of young people. In: Proceedings of the national colloquium "Physical and sports education in Morocco in the era of the new pedagogical orientations of 1991", Regional Pedagogical Centre. 12-13 March 1993, Taza, Morocco.

[19] Canadian Society for Exercise Physiology. Canadian Physical Activity Guidelines and Sedentary Behaviour Guidelines. www.csep.ca

[20] Pineau, C., (1994). Introduction to a didactic of physical education.. Folder EPS $\mathrm{n}^{\circ} 8$, Editions EP\&S. (ISBN-10 : 286713062X) - (ISBN-13 : 978-2867130625).

[21] Elementary school preparatory games guide. Ministry of National Education, higher education, create frameworks and scientific research, Directorate of School Sports Promotion, July, 2011.

[22] Gazorla G., (1987). Programme d'évaluation du jeune français. Direction des sports. Secrétariat d'Etat à la Jeunesse et au Sport: 74 p., january 1987.

[23] Senners P., (1989). The foundations of the PE lesson - From theory to practice. Editions Désirs, 256 p. ISBN: 978-2-91541892-7. 